\title{
miR-5000-3p, miR-5009-3P and miR-552: Potential microRNA biomarkers of side population cells in colon cancer
}

\author{
ZHONG-SHENG XIA $^{1}$, LIN WANG ${ }^{2}$, TAO YU $^{1}$, WA ZHONG $^{1}$, GUO-DA LIAN ${ }^{1}$, \\ DI WU ${ }^{1}$, HUI-MIN ZHOU ${ }^{1}$ and GUANG-CHENG CHEN ${ }^{1}$ \\ Departments of ${ }^{1}$ Gastroenterology and ${ }^{2}$ Pathology, Sun Yat-sen Memorial Hospital, \\ Sun Yat-sen University, Guangzhou 510120, P.R. China \\ Received March 17, 2014; Accepted May 6, 2014
}

DOI: $10.3892 /$ or.2014.3232

\begin{abstract}
Colon cancer is one of the most common cancers in the world. Multidrug resistance is related to poor prognosis of advanced colon cancer. The side population plays an important role in multiple drug resistance (MDR) of colon cancer. MicroRNA biomarkers of the side population of colon cancer is still unknown. In the present study, we aimed to explore miRNA markers of side population (SP) cells of colon cancer. The side population was sorted by flow cytometry. Cell viability was measured using an MTT assay. MicroRNA profiling analysis was performed to compare microRNA expression levels in the SP cells of colon cancer with levels in the non-SP cells of colon cancer. RT-PCR was applied to verify the result obtained from the microRNA profiling analysis. miR-5000-3p, miR-5009-3P and miR-552 were all found to be upregulated in SP cells of the colon cancer cell lines HCT-15, HT-29 and LoVo. RT-PCR confirmed the result from the microRNA profiling analysis. This implied that miR-5000-3p, miR-5009-3P and miR-552 may be potential microRNA biomarkers of the side population in colon cancer, which may provide new specific targets of the side population for the reversal of MDR of colon cancer.
\end{abstract}

\section{Introduction}

Colon cancer is a common gastrointestinal cancer and is the second leading cause of cancer-related death in Western countries (1). The morbidity of colon cancer has been increasing in China during the past 20 years. Colon cancer and lung cancer as well as breast cancer are three types of cancers with the most rapidly increasing rate. The morbidity of colon cancer is $\sim 60 / 100,000$ individuals and its mortality is $\sim 8 / 100,000$ individuals (2). According to these statistics, there are almost 800,000 new patients diagnosed with colon cancer every year

Correspondence to: Dr Zhong-Sheng Xia, Department of Gastroenterology, Sun Yat-sen Memorial Hospital, Sun Yat-sen University, Guangzhou 510120, P.R. China

E-mail: xiazhsh@163.com

Key words: miR-5000-3p, miR-5009-3P, miR-552, microRNA, side population, colon cancer in China. Moreover, almost 100,000 colon cancer patients die from colon cancer every year. Therefore, colon cancer has become a serious social health issue. Most patients with colon cancer are in its advanced stages at the time of diagnosis (3), thus surgical operation is not always a curative solution. Consequently, chemotherapy is extremely important for the treatment of colon cancer. However, the response to most forms of chemotherapy achieved to date is generally limited. Less than $50 \%$ of patients with colon cancer respond to the best regimen of combined chemotherapy. Moreover, among these patients, most of them suffer from recurrence after stopping chemotherapy for some time when relief is obtained (4). This is because colon cancer cells acquire the features of multiple drug resistance (MDR) (5).

The traditional classical mechanism of MDR in cancer cells is that cancer cells express ATP-binding cassette transporters including P-glycoprotein (P-gp), multidrug resistance-associated protein (MRP), lung cancer resistance protein (LRP) and others (6). These transmembrane proteins pump chemotherapeutic drugs out of cancer cells to decrease concentrations of these drugs in cancer cells. Therefore, cancer cells are resistant to these chemotherapeutic drugs. Although MDR reversal agents targeting these ATP-binding cassette transporters including calcium antagonist such as verapamil (7), antisense RNA (8) and siRNA (9) can reverse the MDR of cancer cells in vitro, they do not improve the prognosis of patients when combined with antitumor drugs in vivo particularly in the human body.

The conception of cancer stem cells has provided a new hypothesis for the MDR of cancer in recent years. It is now currently accepted that cancer stem cells play an important role in MDR of cancer cells. Researchers are currently attempting to identify specific markers of cancer stem cells in order to exclusively kill this cell population. Various markers including CD133 (10,11) and CD44 (12) have been regarded as specific markers of cancer stem cells in cancer including colon cancer. However, CD133-negative cancer cells were found to have features of cancer stem cells in some types of cancer $(13,14)$. Therefore, the opinion that CD133 could be regarded as a specific marker of cancer stem cells and a target of MDR of cancer cells is still controversial (15).

The side population of cancer cells is believed to have features of cancer stem cells including self-renewal and 
differentiation ability and multidrug resistance to antitumor drugs $(16,17)$. Side population (SP) cells usually express transmembrane protein such as MDR1, BCRP1 and ABCG2. However, non-side population (non-SP) cells in many types of cancer were also reported to express BCRP1, which suggests that although these transmembrane proteins play a role in the phenotype of SP cells, they are not specific markers of SP cells (18). Behbod et al investigated gene markers of SP cells in breast cancer (19). However, no report exists concerning the microRNA profile comparison between SP and non-SP cells in colon cancer. The present study compared the microRNA profile of SP and non-SP cells in several colon cancer cell lines in order to explore the potential microRNA biomarkers of side population in colon cancer, which may provide new specific targets of the side population for the reversal of MDR of colon cancer.

\section{Materials and methods}

Materials. RPMI-1640 medium, Hoechst 33342, methylthiazol tetrazolium (MTT) and dimethyl sulfoxide (DMSO) were all purchased from Sigma-Aldrich. Fetal bovine serum (FBS) and TRIzol were purchased from Invitrogen. 5-Fluorouracil was purchased from Xudong Haipu Pharmaceutical Co., Ltd. (Shanghai, China). Oxaliplatin was purchased from SanofiSynthelabo Co. Adriamycin was purchased from Pharmacia \& Upjohn Co.. miRNeasy Mini kit was purchased from Qiagen Co.. MicroRNA array analysis was performed using miRCURY ${ }^{\text {тм }}$ LNA array (v.18.0) from Exiqon Co. (Vedbaek, Denmark). A reverse transcriptase kit was provided by Kangchen Bio-tech Inc. (Shanghai, China). PCR amplification was performed using Gene Amp PCR System 9700 from Applied Biosystems. Flow cytometry was performed using BD FACSAria II fluorescence-activated cell sorting system from BD Biosciences.

Cell culture. The human colon cancer cell lines, HCT-15, HT-29 and LoVo, were obtained from the Shanghai Cell Bank, Chinese Academy of Sciences. The three colon cancer cell lines were cultured in RPMI-1640 medium supplemented with $10 \%$ $\mathrm{FBS}$ at $37^{\circ} \mathrm{C}$ in a humidified incubator containing $5 \% \mathrm{CO}_{2}$.

Side population analysis. Side population analysis was performed as described previously, with some modifications (20). Trypsinized cultured cells were washed with PBS and were resuspended at $37^{\circ} \mathrm{C}$ in RPMI-1640 medium supplemented with 5\% FBS. After a 10-min preincubation, the cells were labeled with Hoechst 33342 dye for $90 \mathrm{~min}$ at a concentration of $5 \mu \mathrm{g} / \mathrm{ml}$. Cells were counterstained with $1 \mu \mathrm{g} / \mathrm{ml}$ propidium iodide to labeled dead cells. Next, $1 \times 10^{6}$ viable cells were analyzed and sorted using a BD FACSAia II fluorescence-activated cell sorting system. The Hoechst dye was excited at $355 \mathrm{~nm}$ and its fluorescence was measured at two wavelengths using optical filters 450 DF20 [450/20 nm bandpass filter O (Hoechst blue)] and 635LP [635 nm longpass edge filter (Hoechst red)]. Propidium iodide labeling was measured through a 630/BP30 filter for discrimination of dead cells.

MTT assay. Cell proliferation assays were performed by MTT assay (21). Cells were seeded at $1 \times 10^{4} /$ well in 96-well microtiter plates. After a 24-h incubation, an antitumor drug was added. Then cells were incubated at $37^{\circ} \mathrm{C}$ in $5 \% \mathrm{CO}_{2}$ for $72 \mathrm{~h}$. Then $30 \mu \mathrm{l}$ of $5 \mathrm{mg} / \mathrm{ml}$ MTT solution was added and incubated for $4 \mathrm{~h}$ at $37^{\circ} \mathrm{C}$. Medium and MTT solution were discarded after a 4-h incubation. DMSO $(150 \mu \mathrm{l})$ was added into each well to stop the reaction and shaken for $5 \mathrm{~min}$. The optical density (OD) value was read on a Synergy HT multi-detection microplate reader (Bio-Tek Instruments, Inc., Winooski, VT, USA) at $\lambda=570 \mathrm{~nm}$.

MicroRNA array analysis. MicroRNA array analysis was performed by Kangchen Bio-tech, Inc. (Shanghai, China). The protocol was as follows.

RNA extraction. Total RNA was isolated using TRIzol and the miRNeasy Mini kit according to the manufacturer's instructions, which efficiently recovered all RNA species, including miRNAs. RNA quality and quantity were measured using a Nanodrop spectrophotometer (ND-1000, Nanodrop Technologies) and RNA integrity was determined by gel electrophoresis.

RNA labeling. After RNA isolation from the samples, the miRCURY ${ }^{\mathrm{TM}} \mathrm{Hy}^{\mathrm{TM}} / \mathrm{Hy}^{\mathrm{TM}}$ Power labeling kit (Exiqon) was used according to the manufacturer's guideline for miRNA labeling. One microgram of each sample was 3'-end-labeled with the Hy3 $3^{\mathrm{TM}}$ fluorescent label, using T4 RNA ligase by the following procedure: RNA in $2.0 \mu \mathrm{l}$ of water was combined with $1.0 \mu \mathrm{l}$ of CIP buffer and CIP (Exiqon). The mixture was incubated for $30 \mathrm{~min}$ at $37^{\circ} \mathrm{C}$ and was terminated by incubation for $5 \mathrm{~min}$ at $95^{\circ} \mathrm{C}$. Then $3.0 \mu \mathrm{l}$ of labeling buffer, $1.5 \mu \mathrm{l}$ of fluorescent label (Hy3 $\left.{ }^{\mathrm{TM}}\right), 2.0 \mu \mathrm{l}$ of DMSO, $2.0 \mu \mathrm{l}$ of labeling enzyme were added into the mixture. The labeling reaction was incubated for $1 \mathrm{~h}$ at $16^{\circ} \mathrm{C}$ and terminated by incubation for $15 \mathrm{~min}$ at $65^{\circ} \mathrm{C}$.

Array hybridization. After terminating the labeling procedure, the $\mathrm{Hy}^{\mathrm{TM}}$-labeled samples were hybridized on the miRCURY LNA array (v.18.0) according to the array manual. The total $25 \mu \mathrm{l}$ mixture from $\mathrm{Hy}^{\mathrm{TM}}$-labeled samples with $25 \mu$ l hybridization buffer were first denatured for 2 min at $95^{\circ} \mathrm{C}$, incubated on ice for $2 \mathrm{~min}$ and then hybridized to the microarray for $16-20 \mathrm{~h}$ at $56^{\circ} \mathrm{C}$ in a 12 -Bay hybridization system (Hybridization System; Nimblegen Systems, Inc., Madison, WI, USA), which provides an active mixing action and constant incubation temperature to improve hybridization uniformity and enhance signals. Following hybridization, the slides were achieved, washed several times using wash buffer kit (Exiqon) and finally dried by centrifugation for $5 \mathrm{~min}$ at $400 \mathrm{rpm}$. Then the slides were scanned using the Axon GenePix 4000B microarray scanner (Axon Instruments, Foster City, CA, USA).

Data analysis. Scanned images were then imported into GenePix Pro 6.0 software (Axon) for grid alignment and data extraction. Replicated miRNAs were averaged and miRNAs with intensities $\geq 30$ in all samples were chosen for calculating the normalization factor. Expression data were normalized using the median normalization. After normalization, differentially expressed miRNAs were identified through fold change filtering. To identify differentially expressed miRNAs, we performed a fold change filtering between the two samples from the experiment. The threshold we used to screen upregulated or downregulated miRNAs with a fold change $\geq 2.0$. 

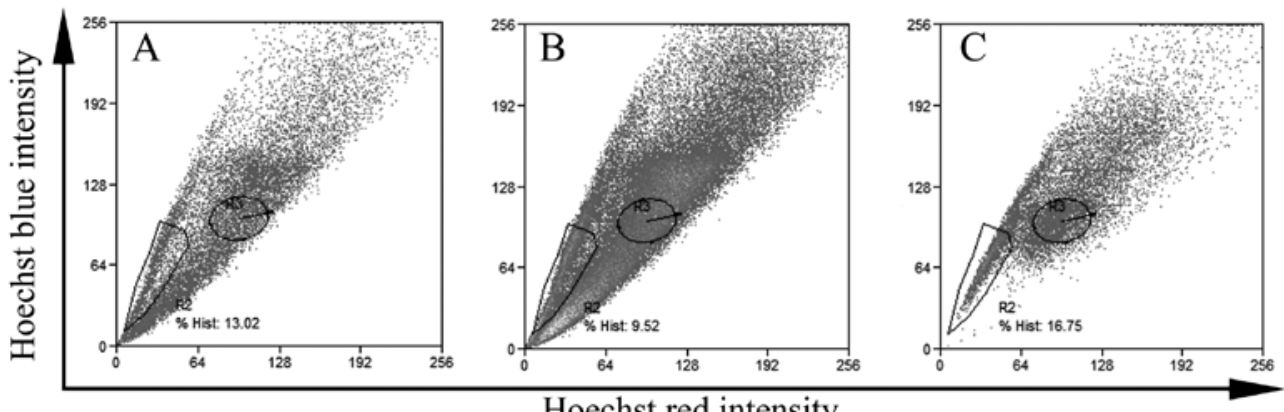

Hoechst red intensity

Figure 1. Side population analysis in three types of colon cancer cell lines. (A) The ratio of SP cells in the HT-29 colon cancer cell line. (B) The ratio of SP cells in the LoVo colon cancer cell line. (C) The ratio of SP cells in the HCT-15 colon cancer cell line. SP cells, side population cells.

Hierarchical clustering was performed using MEV software (v4.6, TIGR).

Verification of microRNA expression using RT-PCR. This part of the experiment was completed by Kangchen Bio-tech, Inc. The protocol in detail was as follows. Total RNAs were isolated from both SP and non-SP cells using TRIzol and the miRNeasy Mini kit according to the manufacturer's instructions. Complementary DNA (cDNA) was synthesized from $0.8 \mu \mathrm{g}$ of total RNA by reverse transcription using MMLV reverse transcriptase (Epicentre). The primers were: RT primer 5'-GTCGTATCCAGTGCGTGTCGTGGAGTCGGCAATT GCACTGGATACGACTCCAAG-3' for miR-5000-3p; 5'-GT CGTATCCAGTGCGTGTCGTGGAGTCGGCAATTGC ACTGGATACGACTTTTGG-3' for miR-5009-3p; 5'-GTC GTATCCAGTGCGTGTCGTGGAGTCGGCAATTGCACT GGATACGACTTGTCTA-3' for miR-552; 5'-CGCTTC ACGAATTTGCGTGTCAT-3' for U6 as an internal control. The PCR amplification was performed in $10 \mu \mathrm{l}$ of PCR mixture containing $2 \mu \mathrm{l}$ of cDNA mixture, $0.5 \mu \mathrm{l}$ of Taq DNA polymerase (Qiagen) and $1 \mu \mathrm{l} 10 \mu \mathrm{M}$ of the primers. The PCR mixture was initially incubated at $95^{\circ} \mathrm{C}$ for $10 \mathrm{~min}$, followed by 40 cycles of denaturation at $95^{\circ} \mathrm{C}$ for $10 \mathrm{sec}$, annealing at $60^{\circ} \mathrm{C}$ for $60 \mathrm{sec}$. The following primer pairs were used for RT-PCR analysis (forward and reverse, respectively): 5'-GGG TCAGGACACTTCTGAA-3' and 5'-CAGTGCGTGTCGTG GAG-3' for miR-5000-3p, with an expected product size of 65 bp; 5'-GGGGGTCCTAAATCTGAAAGT-3' and 5'-GTG CGTGTCGTGGAGTCG-3' for miR-5009-3p, with an expected product size of $65 \mathrm{bp}$; 5'-GGGGGAACAGGTGACT GGT-3' and 5'-GTGCGTGTCGTGGAGTCG-3' for miR-552, with an expected product size of $64 \mathrm{bp} ; 5^{\prime}$-GCTTCGGCAGCAC ATATACTAAAAT-3' and 5'-CGCTTCACGAATTTGCG TGTCAT-3 for U6, with an expected product size of $89 \mathrm{bp}$. U6 was used as an internal control. The relative abundance of each microRNA was normalized by the expression level of U6 RNA, according to the formula: $\Delta \Delta \mathrm{Ct}=\left(\mathrm{Ct}_{\text {sample }}-\mathrm{Ct}_{\mathrm{U} 6 \text { sample }}\right)-$ $\left(\mathrm{Ct}_{\text {control }}-\mathrm{Ct}_{\mathrm{U6control}}\right)$ and the estimated expression ratio was equal to $2^{\Delta \Delta \mathrm{Ct}}$.

\section{Results}

Side population analysis. Colon cancer cells were labeled with Hoechst 33342 and then the side population of colon cancer cells were sorted by flow cytometry. As shown in Fig. 1, there was a certain ratio of SP cells in the different colon cancer cell lines in spite of the different ratio of SP cells. The ratio of SP cells in the HCT-15, HT-29 and Lovo colon cancer cell lines was $16.75,13.02$ and $9.52 \%$, respectively.

Cell viability of SP and non-SP cells in colon cancer cell lines treated with antitumor drugs. SP and non-SP cells sorted from the HCT-15, HT-29 and LoVo colon cancer cell lines were treated with different concentrations of 5-fluorouracil, oxaliplatin and adriamycin, respectively, for 3 days. Then cell viability was measured. As shown in Fig. 2A, the cell viability of the SP cells derived from the HCT-15 colon cancer cell line was significantly higher than that of the non-SP cells at the same concentration of 5-fluorouracil after the HCT-15 colon cancer cells were treated with different concentrations of 5-fluorouracil for 3 days. $\mathrm{IC}_{50}$ of 5-fluorouracil for the SP cells from the HCT-15 colon cancer cell line was $\sim 100 \mu \mathrm{g} / \mathrm{ml}$. In contrast, $\mathrm{IC}_{50}$ of 5-fluorouracil for the non-SP cells from the HCT-15 colon cancer cell line was $\sim 20 \mu \mathrm{g} / \mathrm{ml}$. In other word, in the HCT-15 colon cancer cell line, $\mathrm{IC}_{50}$ of 5-fluorouracil for the SP cells was increased by $\sim 5$-fold compared to that for the non-SP cells. Cell viability of the SP cells derived from the HCT-15 colon cancer cell line was significantly higher than that of the non-SP cells at the same concentration of oxaliplatin after the HCT-15 colon cancer cells were treated with different concentrations of oxaliplatin for 3 days. $\mathrm{IC}_{50}$ of oxaliplatin for the SP cells from the HCT-15 colon cancer cell line was $\sim 24 \mu \mathrm{g} / \mathrm{ml}$. In contrast, $\mathrm{IC}_{50}$ of oxaliplatin for the non-SP cells from the HCT-15 colon cancer cell line was $\sim 6 \mu \mathrm{g} / \mathrm{ml}$. In other word, in the HCT-15 colon cancer cell line, $\mathrm{IC}_{50}$ of oxaliplatin for the SP cells was increased by $\sim 4$-fold than that for the non-SP cells (Fig. 2B). Cell viability of the SP cells derived from the HCT-15 colon cancer cell line was significantly higher than that of the non-SP cells at the same concentration of adriamycin after the HCT-15 colon cancer cells were treated with different concentrations of adriamycin for 3 days. $\mathrm{IC}_{50}$ of adriamycin for the SP cells from the HCT-15 colon cancer cell line was $\sim 60 \mu \mathrm{g} / \mathrm{ml}$. In conrast, $\mathrm{IC}_{50}$ of adriamycin for the non-SP cells from the HCT-15 colon cancer cell line was $\sim 10 \mu \mathrm{g} / \mathrm{ml}$. In other word, in the HCT-15 colon cancer cell line, $\mathrm{IC}_{50}$ of adriamycin for the SP cells was increased by $\sim 6$-fold than that for the non-SP cells (Fig. 2C).

Cell viability of SP cells derived from the HT-29 colon cancer cell line was significantly higher than that of the non-SP cells at the same concentration of 5-fluorouracil after the HT-29 

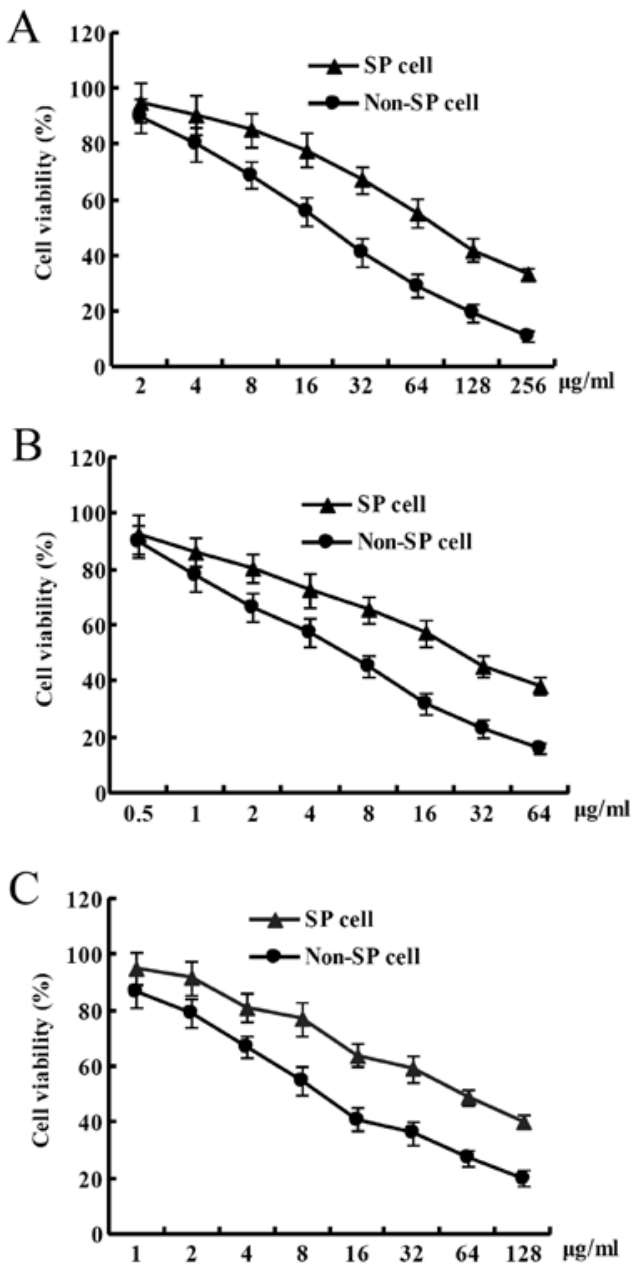

Figure 2. Cell viability of the HCT-15 colon cancer cell line treated with different concentrations of antitumor drugs. The cell viability of the HCT-15 colon cancer cell line treated with different concentrations of (A) 5-fluorouracil, (B) oxaliplatin and (C) adriamycin.

colon cancer cells were treated with different concentrations of 5-fluorouracil for 3 days. $\mathrm{IC}_{50}$ of 5-fluorouracil for the $\mathrm{SP}$ cells from the HT-29 colon cancer cell line was $\sim 50 \mu \mathrm{g} / \mathrm{ml}$. In contrast, $\mathrm{IC}_{50}$ of 5 -fluorouracil for the non-SP cells from the HT-29 colon cancer cell line was $\sim 10 \mu \mathrm{g} / \mathrm{ml}$. In other word, in the HT-29 colon cancer cell line, $\mathrm{IC}_{50}$ of 5-fluorouracil for the SP cells was increased by $\sim 5$-fold than that for the non-SP cells (Fig. 3A). Cell viability of SP cells derived from the HT-29 colon cancer cell line was significantly higher than that of the non-SP cells at the same concentration of oxaliplatin after the HT-29 colon cancer cells were treated with different concentrations of oxaliplatin for 3 days. $\mathrm{IC}_{50}$ of oxaliplatin for the $\mathrm{SP}$ cells from the HT-29 colon cancer cell line was $\sim 15 \mu \mathrm{g} / \mathrm{ml}$. In contrast, $\mathrm{IC}_{50}$ of oxaliplatin for the non-SP cells from the HT-29 colon cancer cell line was $\sim 3 \mu \mathrm{g} / \mathrm{ml}$. In other word, in the HT-29 colon cancer cell line, $\mathrm{IC}_{50}$ of oxaliplatin for the SP cells was increased by $\sim 5$-fold than that for the non-SP cells (Fig. 3B). Cell viability of the SP cells derived from the HT-29 colon cancer cell line was significantly higher than that of the non-SP cells at the same concentration of adriamycin after the HT-29 colon cancer cells were treated with different concentrations of adriamycin for 3 days. $\mathrm{IC}_{50}$ of adriamycin for the SP cells from the HT-29 colon cancer cell line was $\sim 25 \mu \mathrm{g} / \mathrm{ml}$.
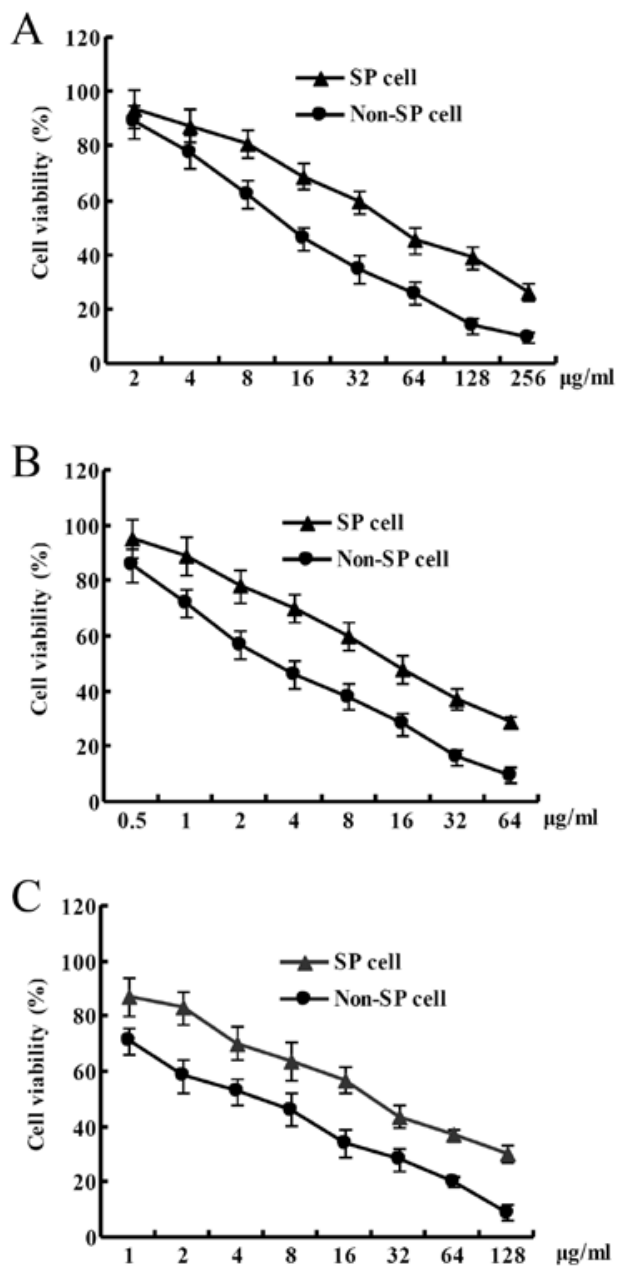

Figure 3. Cell viability of the HT-29 colon cancer cell line treated with different concentrations of antitumor drugs. Cell viability of the HT-29 colon cancer cell line treated with different concentrations of (A) 5-fluorouracil, (B) oxaliplatin and (C) adriamycin.

In contrast, $\mathrm{IC}_{50}$ of adriamycin for the non-SP cells from the HT-29 colon cancer cell line was $\sim 5 \mu \mathrm{g} / \mathrm{ml}$. In other word, in the HT-29 colon cancer cell line, $\mathrm{IC}_{50}$ of adriamycin for the $\mathrm{SP}$ cells was increased by $\sim 5$-fold than that for the non-SP cells (Fig. 3C).

Cell viability of SP cells derived from the LoVo colon cancer cell line was significantly higher than that of the non-SP cells at the same concentration of 5-fluorouracil after the LoVo colon cancer cells were treated with different concentrations of 5-fluorouracil for 3 days. $\mathrm{IC}_{50}$ of 5 -fluorouracil for the $\mathrm{SP}$ cells from the LoVo colon cancer cell line was $\sim 25 \mu \mathrm{g} / \mathrm{ml}$. In contrast, $\mathrm{IC}_{50}$ of 5-fluorouracil for the non-SP cells from the LoVo colon cancer cell line was $\sim 5 \mu \mathrm{g} / \mathrm{ml}$. In other word, in the LoVo colon cancer cell line, $\mathrm{IC}_{50}$ of 5 -fluorouracil for the SP cells was increased by $\sim 5$-fold than that for the non-SP cells (Fig. 4A). Cell viability of the SP cells derived from the LoVo colon cancer cell line was significantly higher than that of the non-SP cells at the same concentration of oxaliplatin after the LoVo colon cancer cells were treated with different concentrations of oxaliplatin for 3 days. $\mathrm{IC}_{50}$ of oxaliplatin for the SP cells from the LoVo colon cancer cell line was $\sim 12 \mu \mathrm{g} / \mathrm{ml}$. In contrast, $\mathrm{IC}_{50}$ of oxaliplatin for the non-SP cells from the LoVo colon cancer cell line was $\sim 2 \mu \mathrm{g} / \mathrm{ml}$. In other word, in 

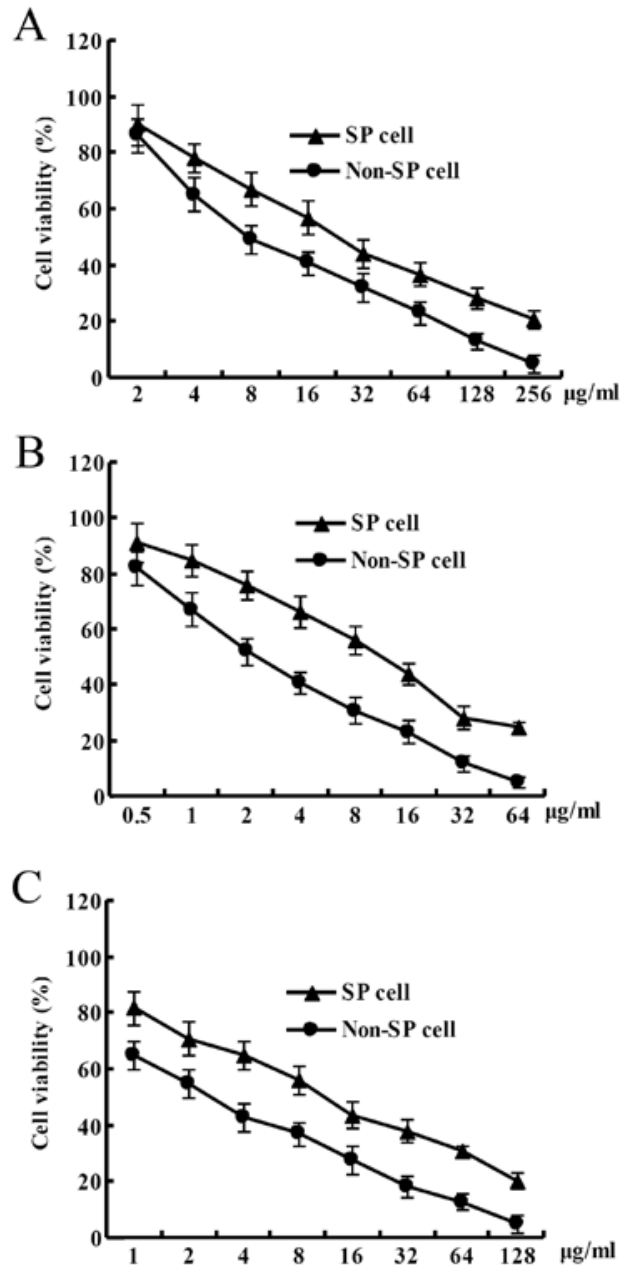

Figure 4. Cell viability of the LoVo colon cancer cell line treated with different concentrations of antitumor drugs. Cell viability of the LoVo colon cancer cell line treated with different concentrations of (A) 5-fluorouracil, (B) oxaliplatin and (C) adriamycin.

the LoVo colon cancer cell line, $\mathrm{IC}_{50}$ of oxaliplatin for the SP cells was increased by $\sim 6$-fold than that for the non-SP cells (Fig. 4B). Cell viability of the SP cells derived from the LoVo colon cancer cell line was significantly higher than that of the non-SP cells at the same concentration of adriamycin after the LoVo colon cancer cells were treated with different concentrations of adriamycin for 3 days. $\mathrm{IC}_{50}$ of adriamycin for the SP cells from the LoVo colon cancer cell line was $\sim 12 \mu \mathrm{g} / \mathrm{ml}$. In contrast, $\mathrm{IC}_{50}$ of adriamycin for the non-SP cells from the LoVo colon cancer cell line was $\sim 3 \mu \mathrm{g} / \mathrm{ml}$. In other word, in the LoVo colon cancer cell line, $\mathrm{IC}_{50}$ of adriamycin for the SP cells was increased by $\sim 4$-fold than that for non-SP cells (Fig. 4C).

MicroRNA profiling of the side population in colon cancer cell lines. MicroRNA profiling of the SP and non-SP cells sorted from the HCT-15, HT-29 and LoVo colon cancer cell lines was carried out using miRCURY LNA array (v.18.0) microRNA chip. The differences in the microRNA profile between the SP and non-SP cells were compared in each colon cancer cell line. microRNAs with fold change $>2$-fold were screened. MicroRNA array analysis indicated that, in the HCT-15 colon cancer cell line, there were 106 upregulated microRNAs in the SP cells including miR-5000-3p,

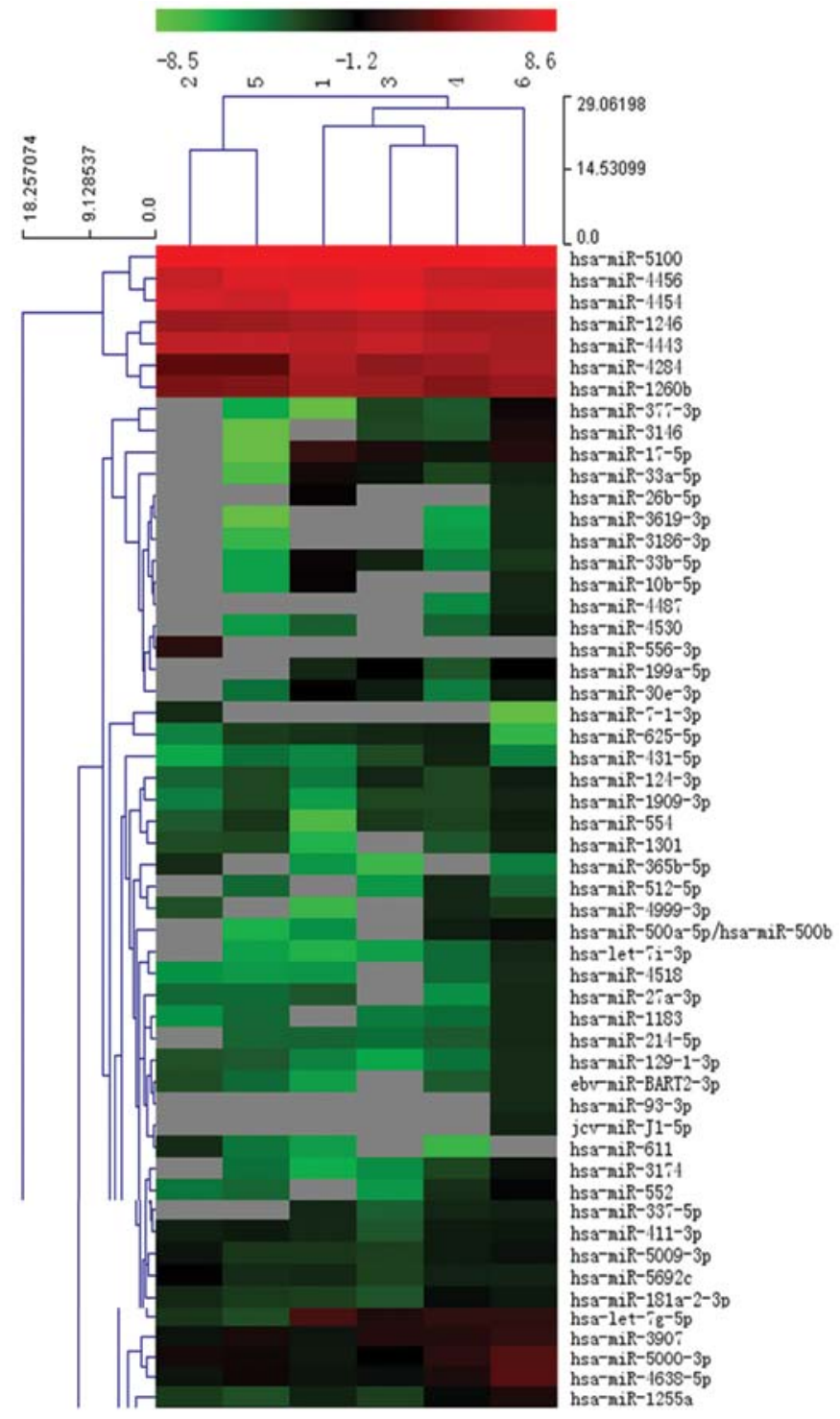

Figure 5. microRNA profiling of SP and non-SP cells in colon cancer cell lines. 1, non-SP cells of the HT-29 cell line; 2, SP cells of the HT-29 cell line; 3, non-SP cells of the LoVo cell line; 4, SP cells of the LoVo cell line; 5 , non-SP cells of the HCT-15 cell line; 6, SP cells of the HCT-15 cell line. SP cells, side population cells; non-SP cells, non-side population cells.

miR-5009-3P, miR-552, miR-17-5p, miR-3146, miR3619-3P and others (Fig. 5); On the other hand, 52 microRNAs were downregulated including miR-133b, miR-4312, miR-4664-3p, miR-4667-3p, miR-4087-5p, miR-940 and others (data not shown). In the HT-29 colon cancer cell line, 58 microRNAs in the SP cells were upregulated including miR-5000-3p, miR-5009-3P, miR-552, miR-611, miR-365b-5p, and others (Fig. 5); However, 63 microRNAs were downregulated including miR-125b-5p, miR-30b-5p, miR-101-3p, miR-7g-5p, miR-125a-5p, miR-130b-3p, and others. (data not shown). In the LoVo colon cancer cell line, 47 microRNAs in the SP cells were upregulated including miR-5000-3p, miR-5009-3P, miR-552, miR-3915, miR-4777-5p, miR-301a-3p and others (some part of the data not shown). However, 22 microRNAs were downregulated including miR-34a-5p, miR-33b-5p, miR30e-3p, miR-199a-5p, miR-125b-3p, miR-1275 and others (data 

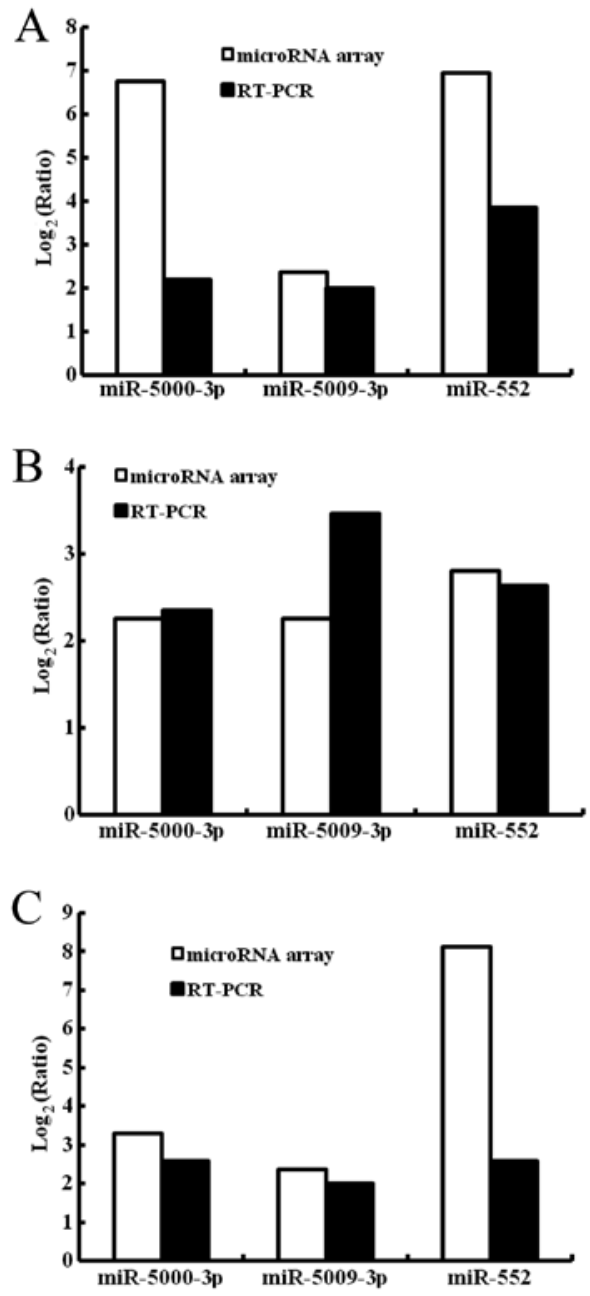

Figure 6. Comparison of the data obtained by RT-PCR and microRNA array analysis in the colon cancer cell lines. Using U6 as an internal control, miR-5000-3p, miR-5009-3P and miR-552 were assessed for expression by RT-PCR. The ratio, representing the relative value of the miRNA expression level, was expressed as a logarithm $\left(\log _{2}\right)$. Corresponding values obtained by microRNA array analysis are presented for comparison. (A) Comparison in the HCT-15 cell line. (B) Comparison in the HT-29 cell line. (C) Comparison in the LoVo cell line.

not shown). From the above mentioned results, we found that miR-5000-3p, miR-5009-3P and miR-552 were upregulated in the SP cells of all three colon cancer cell lines (Fig. 5). However, no microRNA was found to be downregulated in SP cells of all of the three colon cancer cell lines.

Verification of three upregulated microRNAs using RT-PCR. MicroRNA profiling revealed that miR-5000-3p, miR-2009-3P and miR-552 were upregulated in SP cells of all of the three colon cancer cell lines including HCT-15, HT-29 and LoVo. To confirm and validate the results obtained from the microarray, we analyzed the expression of these three microRNAs by RT-PCR. Using U6 as an internal control, relative expression of microRNAs from the SP and non-SP cells was calculated. Then, microRNA expression detected by RT-PCR was compared with the microRNA expression obtained by the microRNA array. The ratios representing microRNA expression changes were $\log _{2}$-transformed in the histograms for these microRNAs. As shown in Fig. 6A, in the HCT-15 colon cancer cell line, expression levels of miR-5000-3p, miR-5009-3P and miR-552 in the SP cells as detected by microRNA array were increased by 6.76-, 2.37- and 6.96-fold, respectively, than those of the non-SP cells while those detected by RT-PCR were increased by $2.20-, 2.01-$ and 3.85 -fold. In the HT-29 colon cancer cell line, expression levels of miR-5000-3p, miR-5009-3P and miR-552 of the SP cells as detected by the microRNA chip were increased by $2.25-, 2.26$ - and 2.81 -fold, respectively, than those of the non-SP cells while those detected by RT-PCR were increased by 2.35-, 3.46- and 2.63-fold (Fig. 6B). In the LoVo colon cancer cell line, expression levels of miR-5000-3p, miR-5009-3P and miR-552 of the SP cells as detected by the microRNA array were increased by 3.28-, 2.35- and 8.13 -fold, respectively, than those of the non-SP cells while those detected by RT-PCR were increased by $2.57-, 2.00$ - and 2.59-fold (Fig. 6C). MicroRNAs including miR-5000-3p, miR5009-3P and miR-552 detected by the microRNA chip were upregulated in SP cells of all of the three colon cancer cell lines. So were microRNAs obtained by RT-PCR. Therefore, the results obtained by RT-PCR verified those obtained by the microRNA chip. This implies that the data obtained from the microRNA array analysis were reliable.

\section{Discussion}

In the present study, we successfully isolated SP cells in colon cancer cell lines using Hoechst 33342 staining. SP cells were first described by Goodell et al (20) and SP cells of several types of malignancies were successfully isolated in subsequent studies (22-27). Haraguchi et al (28) isolated SP cells from gastrointestinal cancer cell lines. Although they reported the gene expression profiles and resistance to chemotherapeutic agents of SP cells derived from the liver cancer cell line Huh7, they did not report the microRNA profiles of SP cells. Schetter et al (29) and Callari et al (30) reported the microRNA profiling of colon cancer cells, but the colon cancer cells were from colon cancer tissues. They did not report the microRNA profiling of SP cells from colon cancer. In the present study, we were able to isolate SP cells from all three colon cancer cell lines (HCT15, HT29, LoVo). The ratio of SP cells in the HCT-15, HT-29 and LoVo colon cancer cell lines was 16.75 , 13.02 and $9.52 \%$, respectively. Inoda et al (31) reported that the ratio of SP cells in the HCT-15, HT-29 and LoVo colon cancer cell lines was 11.1, 10.4 and 9.1\%, respectively. Our data were similar to Inoda's results. This indicates that each type of colon cancer cell line contains a certain ratio of SP cells.

SP and non-SP cells sorted from the HCT-15, HT-29 and LoVo colon cancer cell lines were treated with different concentrations of 5-fluorouracil, oxaliplatin and adriamycin, respectively, for 3 days. Our data showed that cell viability of the SP cells derived from whichever HCT-15, HT-29 or LoVo colon cancer cell line used, was significantly higher than that of the non-SP cells at the same concentration of 5-fluorouracil. This indicated that the SP cells of the colon cancer cell lines were more resistant to 5-fluorouracil. Similar results were found in the presence of oxaliplatin and adriamycin. Therefore the SP cells of the colon cancer cell lines were more resistant to antitumor drugs. Inoda et al reported that SP cells from colon cancer cell lines SW480, HT-29 and HCT-15 showed resistance to chemotherapeutic agents such as irinotecan or 
etoposide (31). All of these findings indicate that SP cells of colon cancer cells are more resistant to chemotherapeutic drugs than non-SP cells. Therefore, SP cells play an important role in multidrug resistance of colon cancer.

Since SP cells play an important role in multidrug resistance of colon cancer, we aimed to investigate the specific biomarkers of SP cells. In a previous study, Behbod et al investigated the gene markers of SP cells in breast cancer (19). Microarray gene profiling suggests that SP cells in breast cancer are a lineage-deficient mammary gland subpopulation expressing key genes involved in cell cycle regulation, development and angiogenesis. In the present study, we performed the microRNA profiling of SP cells in colon cancer cell lines to investigate the microRNA biomarkers of SP cells in colon cancer. miRCURY ${ }^{\mathrm{TM}}$ LNA Array (v.18.0), the newest version of microRNA array which can simultaneously detect hundreds of microRNAs, was used to perform the microRNA profiling of SP cells in colon cancer cell lines. In the HCT-15, HT-29 and LoVo colon cancer cell lines, three microRNAs including miR-5000-3p, miR-5009-3P and miR-552 were upregulated in SP cells of all of these three colon cancer cell lines. However, no microRNA was downregulated in SP cells of all three colon cancer cell lines. Furthermore, the findings were also confirmed by RT-PCR. In previous studies, Schetter et al (29) and Callari et al (30) reported the microRNA profiling of colon cancer cells. However, the colon cancer cells were from colon cancer tissues. Link et al (32) reported fecal microRNA profiling of colon cancer whereas the stool samples were from patients with colon cancer and healthy volunteers. Hofsli et al (33) investigated the serum microRNA profile of colon cancer while the serum samples were from patients with colon cancer and healthy controls. Although Zhang et al (34) and Fang et al (35) investigated the microRNA expression profile of colon cancer stem-like cells, they collected colon cancer stem-like cells based on CD133 or CD133/CD44 not SP cells. In addition to this, they compared the microRNA expression profile of colon cancer stem cells with non-stem cells only using one type of colon cancer cell line. No study on the microRNA profiling of SP cells of colon cancer was reported in all of the above studies. Therefore, the present study was the first report on microRNA profiling of SP cells in colon cancer.

In the present study, three microRNAs were found to be upregulated in SP cells of all three colon cancer cell lines including HCT-15, HT-29 and LoVo. These three microRNAs including miR-5000-3p, miR-5009-3P and miR-552 may be potential microRNA biomarker candidates of SP cells in colon cancer. As we know, SP cells play an important role in multidrug resistance of colon cancer. Thus, these three microRNAs may also be potential targets for the treatment of colon cancer. In future research, antisense RNA targeted to one of these three microRNAs will be used to inhibit the specific microRNA expression to investigate whether antisense RNA targeting to $\mathrm{miR}-5000-3 \mathrm{p}, \mathrm{miR}-5009-3 \mathrm{P}$ or miR-552 reverses the multidrug resistance of colon cancer.

\section{Acknowledgements}

This study was supported by Guangdong Natural Science Foundation, China (9451008901002424).

\section{References}

1. Hawk ET,Limburg PJ and Viner JL: Epidemiology and prevention of colorectal cancer. Surg Clin North Am 82: 905-941, 2002.

2. Sung J: Does fecal occult blood test have a place for colorectal cancer screening in China in 2006? Am J Gastroenterol 101: 213-215, 2006.

3. Taal BG, Van Tinteren H and Zoetmulder FA: Adjuvant 5FU plus levamisole in colonic or rectal cancer: improved survival in stage II and III. Br J Cancer 85: 1437-1443, 2001.

4. Douillard JY, Cunningham D, Roth AD, et al: Irinotecan combined with fluorouracil compared with fluorouracil alone as first-line treatment for metastatic colorectal cancer: a multicentre randomised trial. Lancet 355: 1041-1047, 2000.

5. Redmond SM, Joncourt F, Buser K, et al: Assessment of P-glycoprotein, glutathione-based detoxifying enzymes and $\mathrm{O}^{6}$-alkylguanine-DNA alkyltransferase as potential indicators of constitutive drug resistance in human colorectal tumors. Cancer Res 51: 2092-2097, 1991.

6. van den Heuvel-Eibrink MM, Sonneveld P and Pieters R: The prognostic significance of membrane transport-associated multidrug resistance (MDR) proteins in leukemia. Int J Clin Pharmacol Ther 38: 94-110, 2000.

7. Tsuruo $\mathrm{T}$, lida $\mathrm{H}$, Tsukagoshi $\mathrm{S}$, et al: Overcoming of vincristine resistence in $\mathrm{P} 388$ leukemia in vivo and in vitro through enhanced cytotoxicity of vincristine and vinblastine by verapamil. Cancer Res 41: 1967-1972, 1981.

8. Gao Z, Fields JZ and Boman BM: Co-transfection of MDR1 and MRP antisense RNAs abolishes the drug resistance in multidrug resistant human lung cancer cells. Anticancer Res 18: 3073-3076, 1998.

9. Xia Z, Zhu Z, Zhang L, et al: Specific reversal of MDR1/ $\mathrm{P}$-gp-dependent multidrug resistance by RNA interference in colon cancer cells. Oncol Rep 20: 1433-1439, 2008.

10. Todaro M,Francipane MG, Medema JP and Stassi G: Colon cancer stem cells: promise of targeted therapy. Gastroenterology 138: 2151-2162, 2010.

11. Todaro M, Alea Mp, Di Stefano AB, et al: Colon cancer stem cells dictate tumor growth and resist cell death by production of interleukin-4. Cell Stem Cell 1: 389-402, 2007.

12. Lee CJ, Dosch J and Simeone DM: Pancreatic cancer stem cells. J Clin Oncol 26: 2806-2812, 2008.

13. Zheng X, Shen G, Yang X and Liu W: Most C6 cells are cancer stem cells: evidence from clonal and population analyses. Cancer Res 67: 3691-3697, 2007.

14. Beier D, Hau P, Proescholdt M, et al: CD133+ and CD133 glioblastoma-derived cancer stem cells show differential growth characteristics and molecular profiles. Cancer Res 67: 4010-4015, 2007.

15. Sakariassen $P \emptyset$, Immervoll $\mathrm{H}$ and Chekenya $\mathrm{M}$ : Cancer stem cells as mediators of treatment resistance in brain tumors: status and controversies. Neoplasia 9: 882-892, 2007.

16. Szotek PP, Pieretti-Vanmarcke R, Masiakos PT, et al: Ovarian cancer side population defines cells with stem cell-like characteristics and Mullerian Inhibiting Substance responsiveness. Proc Natl Acad Sci USA 103: 11154-11159, 2006.

17. Hirschmann-Jax C, Foster AE, Wulf GG, et al: A distinct 'side population' of cells with high drug efflux capacity in human tumor cells. Proc Natl Acad Sci USA 101: 14228-14233, 2004.

18. Zhou S, Schuetz JD, Bunting KD, et al: The ABC transporter Bcrp1/ABCG2 is expressed in a wide variety of stem cells and is a molecular determinant of the side-population phenotype. Nat Med 7: 1028-1034, 2001.

19. Behbod F, Xian W, Shaw CA, et al: Transcriptional profiling of mammary gland side population cells. Stem Cells 24: 1065-1074, 2006.

20. Goodell MA, Brose K, Paradis G, et al: Isolation and functional propertied of murine hematopoietic stem cells that are replicating in vivo. J Exp Med 183: 1797-1806, 1996.

21. Carmichael J, Degraff WG, Gazdar AF, et al: Evaluation of a tetrazolium-based semiautomated colorimetric assay: assessment of chemosensitivity testing. Cancer Res 47: 936-942, 1987.

22. Murase M, Kano M, Tsukahara T, et al: Side population cells have the characteristics of cancer stem-like cellscancer-initiating cells in bone sarcomas. Br J Cancer 101: 1425-1432, 2009.

23. Kondo T, Setoguchi T and Taga T: Persistence of a small subpopulation of cancer stem-like cells in the C6 glioma cell line. Proc Natl Acad Sci USA 101: 781-786, 2004. 
24. Chiba T, Kita K, Zheng YW, et al: Side population purified from hepatocellular carcinoma cells harbors cancer stem cell-like properties. Hepatology 44: 240-251, 2006.

25. Ho MM, Ng AV, Lam S and Hung JY: Side population in human lung cancer cell lines and tumors is enriched with stem-like cancer cells. Cancer Res 67: 4827-4833, 2007.

26. Mitsutake N, Iwao A, Nagai K, et al: Characterization of side population in thyroid cancer cell lines: cancer stem-like cells are enriched partly but not exclusively. Endocrinology 148: 1797-1803, 2007.

27. Wang J, Guo LP, Chen LZ, et al: Identification of cancer stem cell-like side population cells in human nasopharyngeal carcinoma cell line. Cancer Res 67: 3716-3724, 2007.

28. Haraguchi N, Utsunomiya T, Inoue H, et al: Characterization of a side population of cancer cells from human gastrointestinal system. Stem Cells 24: 506-513, 2006.

29. Schetter AJ, Leung SY, Sohn JJ, et al: MicroRNA expression profiles associated with prognosis and therapeutic outcome in colon adenocarcinoma. JAMA 299: 425-436, 2008.
30. Callari M, Dugo M, Musella V, et al: Comparison of microarray platforms for measuring differential microRNA expression in paired normal/cancer colon tissues. PLoS One 7: 1-15, 2012.

31. Inoda $\mathrm{S}$, Hirohashi $\mathrm{Y}$, Torigoe $\mathrm{T}$, et al: Cytotoxic $\mathrm{T}$ lymphocytes efficiently recognize human colon cancer stem-like cells. Am J Pathol 178: 1805-1813, 2011.

32. Link A, Balaguer F, Shen Y, et al: Fecal MicroRNAs as novel biomarkers for colon cancer screening. Cancer Epidemiol Biomarkers Prev 19: 1766-1774, 2010.

33. Hofsli E, Sjursen W, Prestvik WS, et al: Identification of serum microRNA profiles in colon cancer. Br J Cancer 108: 1712-1719, 2013.

34. Zhang H, Li W, Nan F, et al: MicroRNA expression profile of colon cancer stem-like cells in HT29 adenocarcinoma cell line. Biochem Biophys Res Commun 404: 273-278, 2011.

35. Fang Y, Xiang J, Chen ZY, et al: miRNA expression profile of colon cancer stem cells compared to non-stem cells using the SW1116 cell line. Oncol Rep 28: 2115-2124, 2012. 